\title{
Effects of Substrate Temperature on Adsorption of Hydrocarbon Species Generated in Methane Plasma
}

\author{
Masanori Shinohara, Ken Cho, Yoshinobu. Matsuda, \\ Hiroshi Fujiyama ${ }^{*}$, Keishi Okamoto ${ }^{* *}$, Tatsuyuki Nakatani, ${ }^{* * *}$ \\ Dep. of Electrical and Electronic Engineering, Nagasaki University, 1-14 Bunkyo, Nagasaki 852-8521, Japan \\ Fax: 81-95-819-2542, e-mail: sinohara@nagasaki-u.ac.jp \\ "Graduate school of Science and Technology, Nagasaki University, 1-14 Bunkyo, Nagasaki 852-8521, Japan \\ "Toyo Advanced Technologies Co., Ltd., 5-3-38 Ujina-higashi Ninami-ku Hiroshima, 734-8501, Japan
}

We investigated the effects of substrate temperature on the deposition rates and the configuration of the hydrocarbon species in the film during film deposition in order to elucidate the film-deposition process. We have used infrared spectroscopy in multiple internal absorption reflection geometry (MIR-IRAS) to elucidate the configuration of the hydrocarbon species. The deposition rates drastically decreased as the substrate temperatures increased up to $200^{\circ} \mathrm{C}$. IRAS data revealed that the intensity of the peak due to the $\mathrm{CH}_{3}$ species decreased as the substrate temperature increased up to $200^{\circ} \mathrm{C}$. This suggested that the $\mathrm{CH}_{3}$ species preferentially decomposed and/or was etched during film growth at higher substrate temperatures.

Key words methane plasma; infrared absorption; hydrocarbon, substrate temperatures

\section{INTRODUCTION}

Amorphous carbon films are attracting attention nowadays because of their unique properties such as chemical and mechanical stability, bio-compatibility, low friction, optical transparency, and changeable band gap. Moreover, a film can be easily deposited at low temperature using the plasma-enhanced chemical vapor deposition (PECVD) method. The film can then be used in various industrial applications such as a coating material for optical, mechanical, and medical apparatus, and electronic devices [1]. The precise control of deposition is required in the near future to use these films in the micro-fabrication process. Their growth mechanisms need to be understood in order to realize the control of deposition at an atomic level. The details of mechanisms, especially the chemical states of the adsorbed species during growth, have not yet been entirely understood. We have used infrared absorption spectroscopy in multiple internal reflection geometry (MIR-IRAS) to investigate the adsorption process of the hydrocarbon species generated in methane plasma at room temperature [2-3] followed by the thermal decomposition process of hydrocarbon species in a vacuum [4].

In this study, we investigate the dependence of the film-deposition process on substrate temperature. We measured the film thickness and calculated the film-deposition rates. Further, we measured the IRAS spectra during the carbon film growth. We found that as the substrate temperatures increased up to $200^{\circ} \mathrm{C}$, the deposition rates drastically decreased and the density of the $\mathrm{CH}_{3}$ species in the film simultaneously decreased.

\section{EXPERIMENTS}

The system used in this study was a stainless-steel chamber equipped with an IRAS monitoring system, a radio frequency (RF) plasma source, and a gas-delivery system, as is schematically illustrated in Fig. 1. The base pressure of the chamber was maintained below $1 \times 10^{-6}$ Torr. Plasma was generated by feeding 13.56-MHz RF power to a coil wrapped around a 3-cm-diameter glass tube through a matching box. Methane plasma was generated using $40 \mathrm{~W}-\mathrm{RF}$ power at a methane pressure of 35 mTorr. The gas-flow rate of the methane gas was set at $10 \mathrm{sccm}$. A Si sample was used as a substrate, and it was placed at a distance of approximately $25 \mathrm{~cm}$ from the center of the RF antenna in the vacuum chamber. To control the substrate temperature, a new sample holder was installed; it was made of $\mathrm{Cu}$ with dimensions of 40 $\times 35 \times 5 \mathrm{~mm}$ and had a heating system. The temperatures of the holder were measured using a chromel-alumel thermocouple during the methane plasma exposure to predict the substrate temperatures. The substrate temperature without the additional heater heating was approximately $35^{\circ} \mathrm{C}$ due to heating by plasma radiation. The sample holder was grounded in all the experiments.

The Si samples used in this study were obtained from n-type P-doped $\mathrm{Si}(100)$ wafers with resistivities of approximately $10 \Omega \mathrm{cm}$. The samples used in these experiments had dimensions of $0.5 \times 10 \times 40 \mathrm{~mm}$, with $45^{\circ}$ bevels on each of the short edges. The sample used

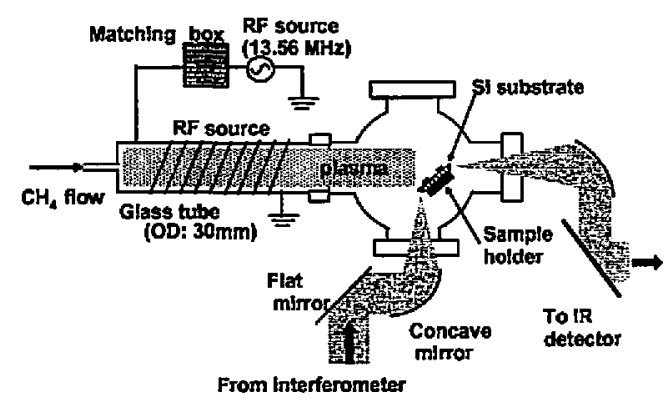

Fig. 1 Experimental setup 
in this experiment was longer than the sample holder so that the sample holder would not interfere with the path of the infrared light.

The film thickness was also verified by measuring the steps formed with masks using a profile meter (Mitsutoyo) after the film deposition.

The chemical state of the surface during the plasma exposure was monitored by the MIR-IRAS. This technique is fairly sensitive [5]. We measured the IRAS spectra in the $\mathrm{C}-\mathrm{H}$ stretching vibration region. As the reference spectrum in the $\mathrm{C}-\mathrm{H}$ stretching vibration regions, we used the spectrum of the thin chemical-oxide layers on the $\mathrm{Si}$ surface, which was produced by surface treatment in boiled $\mathrm{H}_{2} \mathrm{SO}_{4} / \mathrm{H}_{2} \mathrm{O}_{2}$ solution. The infrared radiation that exited an interferometer (BOMEM MB-100) was focused at normal incidence on one of the two bevels of the sample and traveled through the wafer with internal reflection. The radiation that exited the sample at the other bevel was focused on a liquid- $\mathrm{N}_{2}$-cooled $\mathrm{HgCdTe}$ (MCT) detector.

\section{RESULTS AND DISCUSSION}

Figure 2 shows the deposition rates as a function of the substrate temperature. This graph indicates that the film-deposition rates further decreased at higher substrate temperatures; the rates drastically decreased while the substrate temperatures increased from 35 to $200{ }^{\circ} \mathrm{C}$. This result is consistent with the previous results of carbon-film deposition using methane gas as a source gas [6-7]. It appears that this deposition process has negative activation energy. This phenomenon was explained as follows: at higher temperature, hydrocarbon species evaporated from the substrate and hydrogen radicals etched the carbon film [7]. However, it is unclear as to which chemical species were changed in the film due to a remarkable decrease in the deposition rates.

Further, we measured the IRAS spectra of the amorphous carbon film deposited at different substrate temperatures, as shown in Fig. 3. All the films had a thickness of $100 \mathrm{~nm}$. All the spectra show three distinct peaks at around 2870,2930 , and $2960 \mathrm{~cm}^{-1}$. We can assign the peaks at 2870 and $2960 \mathrm{~cm}^{-1}$ to the polymer-like $\mathrm{sp}^{3}-\mathrm{CH}_{3}$ species, and the peak at 2930

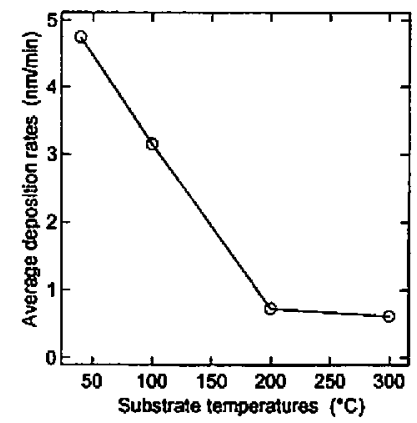

Fig.2 Average deposition rates as a function of substrate temperatures. Average deposition rates were averaged with the deposition rates of several films. Each deposition rate of each film was calculated assuming a linear deposition rate by dividing the average film thickness at several points by the deposition time.

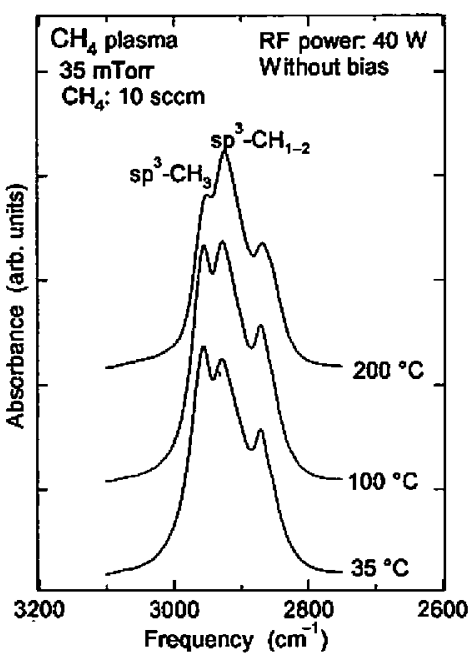

Fig. 3 The infrared absorption spectra observed in the_carbon film deposited at 35,100 , and $200^{\circ} \mathrm{C}$. The three films were nearly $100 \mathrm{~nm}$ thick

$\mathrm{cm}^{-1}$ to the polymer-like $\mathrm{sp}^{3}-\mathrm{CH}_{2}$ and/or $\mathrm{sp}^{3}-\mathrm{CH}$ species [8-9]. Based on the present results, we suggest that hydrogenated amorphous carbon films $(\mathrm{a}-\mathrm{C}: \mathrm{H})$ were formed on the $\mathrm{Si}$ surface during methane plasma irradiation. As the substrate temperatures were increased, the $\mathrm{CH}_{3}$ peak decreased in intensity but the $\mathrm{CH}_{1-2}$ peak had nearly constant intensity. Taking into account that these films have the same thickness, it is suggested that the number of carbon-carbon (C-C) bonds increased with the substrate temperature. What causes this difference?

We investigated the absorption process of the chemical species generated in the methane plasma. Figure 4 shows the IRAS spectra observed in the $\mathrm{Si}$

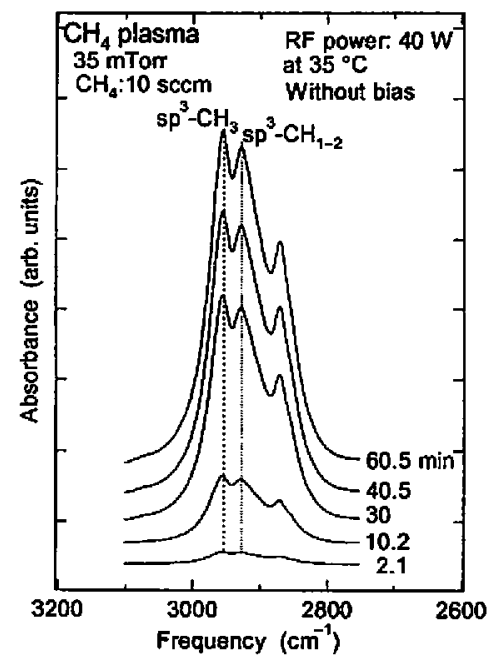

Fig. 4 Infrared spectra observed in a $\mathrm{Si}$ surface exposed to the methane plasma at a substrate temperature of $200^{\circ} \mathrm{C}$. The figure attached to each spectrum indicates the exposure time in minutes. 


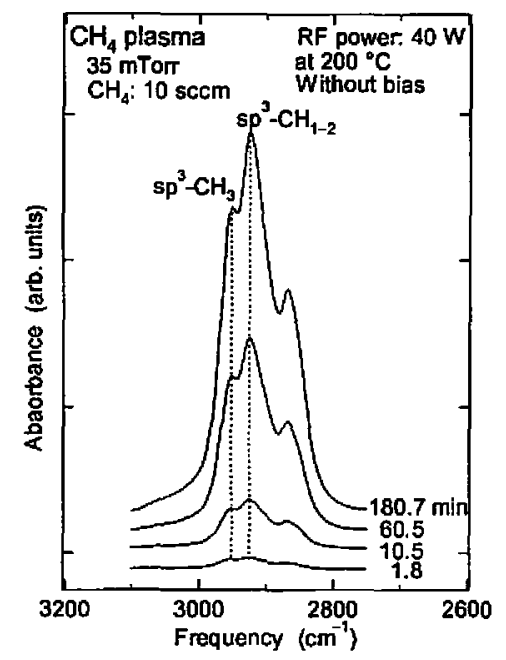

Fig. 5 The infrared spectra observed in a $\mathrm{Si}$ surface exposed to the methane plasma at the substrate temperature of $200^{\circ} \mathrm{C}$. The figure attached to each spectrum indicates the exposure time in minutes.

surface exposed to methane plasma without additional heating. The three peaks can be observed from the initial stage of exposure. This means that the $\mathrm{CH}_{3}, \mathrm{CH}_{2}$, and $\mathrm{CH}$ species existed from the initial stage, similar to those observed in the higher-exposure regions; this might suggest that these chemical species $\left(\mathrm{CH}_{3}, \mathrm{CH}_{2}\right.$, and $\mathrm{C}_{2} \mathrm{H}_{5}$ ) were generated in the methane plasma and were adsorbed on the $\mathrm{Si}$ surface. We will elucidate these points in future works. The entire peak intensity increased with the exposure time. This indicates that as the exposure time is increased, the chemical species on the Si surface gradually increased and then the film deposit grew increasingly thicker. Here, we noticed that the spectral shapes had not changed even after the exposure time was increased.

Figure 5 shows the IRAS spectra of the $\mathrm{Si}$ surface exposed to methane plasma with the substrate heated at $200{ }^{\circ} \mathrm{C}$. In these spectra, the three peaks can be seen from the initial stage of exposure. The entire peak intensity was further increased with the increasing exposure time, similar to the previous case. This indicates that as the exposure time was increased, the chemical species deposited on the Si surface gradually increased, and then the film deposit became increasingly thicker. Unlike the previous case, it appears that the spectral shapes had changed as the exposure time was increased. These facts imply that the $\mathrm{CH}_{3}, \mathrm{CH}_{2}$, and $\mathrm{CH}$ species existed from the initial stage similar to those observed in the higher-exposure regions; but that the density ratio of each species had changed.

In order to clarify the temporal changes of the spectral shapes during the initial film deposition, we observe the intensity ratios of the peak located at $2960 \mathrm{~cm}^{-1}$, which is due to $\mathrm{CH}_{3}$ species, to the peak at $2930 \mathrm{~cm}^{-1}$, which is due to the $\mathrm{CH}$ and/or $\mathrm{CH}_{2}$ species. Figure 6 shows the peak intensity ratios obtained from both Fig. 4 and Fig. 5 plotted as a function of the exposure time. Each temperature denotes the substrate temperature when the surface was exposed to the methane plasma. The peak

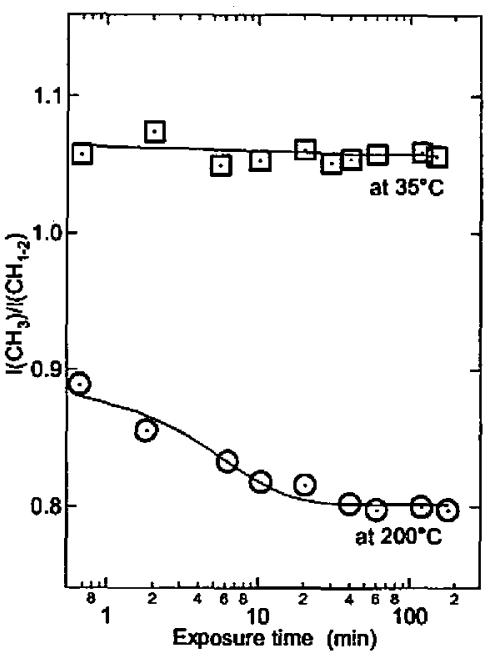

Fig. 6 The intensity ratios of the peak at $2960 \mathrm{~cm}^{-1}$ to that at $2930 \mathrm{~cm}^{-1}$ was plotted as a function of the plasma exposure time. The open squares ( $\square$ ) were obtained from the Si surface exposed to the methane plasma without an additional heating. The open circles (o) were obtained from that with heating at $200^{\circ} \mathrm{C}$

intensity ratios obtained from the film deposition at $35{ }^{\circ} \mathrm{C}$ remained the same even if the exposure time was longer. On the other hand, the ratios obtained from the deposition process at $200^{\circ} \mathrm{C}$ decreased, as the exposure time was longer until around $20 \mathrm{~min}$. This indicates that the density of the $\mathrm{CH}_{3}$ species decreased during the film deposition at $200{ }^{\circ} \mathrm{C}$ as the exposure time was longer-approximately $20 \mathrm{~min}$; thereafter, the ratios did not change. This indicates that the density ratio of the $\mathrm{CH}_{3}$ species to the $\mathrm{CH}_{1-2}$ species remained constant after the 20-min exposure. Here, the film thickness was approximately $14 \mathrm{~nm}$, considering the deposition rates obtained from Fig.2. The density ratio of the $\mathrm{CH}_{3}$ species to the $\mathrm{CH}_{1-2}$ species remained constant after a thickness of approximately $14 \mathrm{~nm}$ was attained. Here, it maybe considered that the ratio always changes at such film thicknesses during film deposition. However, in our previous description, we stated that the peak intensity ratios always remained constant when we obtained the ratios from the film deposited at $35^{\circ} \mathrm{C}$ during the deposition, in less than $2 \mathrm{~min}$; here, the film thickness was less than $10 \mathrm{~nm}$ for the deposition rate shown in Fig. 2. This implies that the peak intensity ratios-in other words, the density ratios of the $\mathrm{CH}_{\mathrm{x}}$ species--changed only at $200^{\circ} \mathrm{C}$.

Why did the density ratio of the $\mathrm{CH}_{3}$ species change during film deposition? The chemical species generated in the plasma should not change. If so, the same change must be observed during the film deposition at $35^{\circ} \mathrm{C}$. Therefore, we suggest that, as compared with the $\mathrm{CH}_{\mathrm{I}-2}$ species, the density of the $\mathrm{CH}_{3}$ species in the film decreased during the film deposition at high substrate temperatures. We attribute this decrease to two reasons. First, etching or evaporation of the $\mathrm{CH}_{3}$ species: the $\mathrm{CH}_{3}$ species is preferentially etched by methane plasma or is preferentially hydrogenated to form a volatile methane molecule. The density of hydrogen radicals is approximately $1 \times 10^{13} \mathrm{~cm}^{-3}$ in this methane plasma, 
resulting from an actinometrical measurement. The details of the measurements will be described elsewhere. Second, the $\mathrm{CH}_{3}$ species is decomposed to the $\mathrm{CH}_{1-2}$ species with the breaking of the $\mathrm{C}-\mathrm{H}$ bonds by the hydrogen radicals and $\mathrm{CH}_{3}$ radicals during the plasma exposure. In future works, we will elucidate the detailed mechanism of the decrease in the $\mathrm{CH}_{3}$ species during the plasma exposure.

\section{CONCLUSION}

We investigate the effects of the substrate temperature on the adsorption of hydrocarbon species generated in the methane plasma, using infrared absorption spectroscopy in multiple internal reflection geometry (MIR-IRAS) and deposition rates. The deposition rates drastically decreased as the substrate temperatures increased from room temperature to $200^{\circ} \mathrm{C}$. IRAS data revealed that the density of the $\mathrm{CH}_{3}$ species drastically decreased as substrate temperatures increased up to $200{ }^{\circ} \mathrm{C}$. Moreover, the relative density of the $\mathrm{CH}_{3}$ species decreased during film deposition at higher temperature, compared with the density of the $\mathrm{sp}^{3}-\mathrm{CH}_{1-2}$ species. This suggested that the $\mathrm{CH}_{3}$ species preferentially decomposed and/or was etched during film growth at high substrate temperatures.

\section{ACKNOWLEDGEMENTS}

This research was partially supported by a Grant-in-Aid for Young Scientists (B), No. 15760023 (2003 - 2006) and No. 18740354 (2006-2008) from the Ministry of Education, Culture, Sports, Science and Technology (MEXT) of Japan. We would like to thank Prof. M. Niwano and Dr. Y. Kimura (RIEC, Tohoku Univ.) for their continuous supports and encouragements. Prof. A. Matsuda (Tokyo Univ. of Sci.) was also acknowledged for his fruitful discussion. Prof. $H$. Fukunaga, Prof. M. Nakano, and Dr. T. Yanai were acknowledged for their help in the measurements with a profile-meter. Mr. M. Morita and Mr. T. Shibasaki were acknowledged for their experimental assistance.

\section{References}

[1] Grill, Diam. Relat. Mater. 8, 428-434 (1999).

[2] M. Shinohara, T. Kuwano, Y. Kimura and M. Niwano, Thin Solid Films 435, 13-18 (2003).

[3] M. Shinohara, T. Katagiri, K. Iwatsuji, H. Shibata, Y. Matsuda, and H. Fujiyama, Thin Solid Films 506-507, 710-714 (2006).

[4] M. Shinohara, K. Iwatsuji, T. Katagiri, H. Shibata, Y. Matsuda and H. Fujiyama, Appl. Sur. Sci. 252, 8589-8592 (2006).

[5] Y.J. Chabal, Surf. Sci. Rep. 8, 211-357 (1988).

[6] N. Mutsukura, Vacuum 56, 129-132 (2000).

[7] A. von Kendall and W. Möller, J. Appl. Phys. 75, 7718-7727 (1994).

[8] S. Naito, N. Ito, T. Hattori, and T, Goto, Jpn. J. Appl. Phys. 34, 302-303 (1995).

[9] A. Vanhulsel, J.-P. Celis, E. Dekempeneer, J. Meneve, J. Smeets, K. Vercammen, Diamond Relat. Mater. 8, 1193-1197 (1999). 